\title{
On the Question of Integrating Spirituality with Counselling in India
}

\author{
Thomas Joseph Parayil* and Tony Sam George ${ }^{\dagger}$
}

\begin{abstract}
This paper explores the therapists' views and experience on spiritual components in counselling. Qualitative data were collected through semi-structured interviews, and thematic analysis used. The participants were nine mental health professionals from different backgrounds with 15 to 30 years of experience in the field. The four main themes that emerged are faith in God, the power of prayer, forgiveness and wholesome treatment process.
\end{abstract}

Keywords: Counselling, Healing, Integration, Spirituality, Therapist

\section{Introduction and Background}

The assessment of spirituality is an emerging area of interest among the mental health professionals in the western countries. Little research has been undertaken in India in this direction. In the United States, there is interest from mental health professionals on

* Dharmaram Vidya Kshetram, Bengaluru, India; thomasparayil04@yahoo.co.in

† Department of Psychology, Christ University, Bengaluru, India; tony.sam.george@christuniversity.in 
the spiritual needs of the clients. According to a study by Young, Wiggins-Frame and Cashwell (2007), "interest in integrating spirituality into the counselling profession has increased, but a full integration of spirituality into counselling has not been realised" (p.26).In addition, the educational and training response by the counselling profession has not been given due importance. Globalisation, multicultural research and Western interest in Eastern thought have contributed to the advancement of multicultural psychology. While spirituality plays such an important role in non-Western cultures, it tends to occupy only a minor area of cross-cultural research in India. Its roots in ancient philosophical texts such as the Bhagavad Gita make Indian psychology not only grounds on a rich tradition and one deserving of close study, but also a template for how the Western researchers can better understand indigenous spiritual perspectives. From this vantage point, spirituality and Indian psychology can contribute to the rest of the world.

The researchers have felt the need of spirituality in counselling from their cumulative experience of over thirty years in the field of counselling and psychotherapy. In addition, the researchers are also convinced that the medium of therapeutic relationship plays a crucial role in counselling interventions. Moreover, the rapport building communicates the very elements of positive dimensions of spirituality: trust, optimism, hope and respect.

\section{Spirituality}

There are a good number of definitions for spirituality. According to Harold G Koenig (2001), "Spirituality is the personal quest for understanding answers to ultimate questions about life, about meaning and about relationship to the sacred or transcendent, which may (or may not) lead to or arise from the development of religious rituals and the formation of community" (p.17). For some, it gives meaning to life, it is an ability to connect with the higher power, and for others it is interconnectedness.

In every human being, there seems to be a spiritual dimension, a quality that goes beyond religious affiliation that strives for 
inspiration, reverence, awe, meaning and purpose even in those who do not believe in God. The spiritual dimension helps people to be in harmony with the universe, strives for answers about the infinite and comes essentially in focus in times of emotional stress, physical (and mental) illness, loss, bereavement and death (Murray \&Zentner, 1989).It is crucial for psychotherapists to learn from spirituality, religion and integrate appropriately in their interventions.

One can trace the genesis of counselling to a spiritual experience between individuals with the sole intention of bringing positive change in people's lives to improve their well-being, alleviate distress and maladjustment, resolve crises, and increase their abilities to live better functioning lives. It is spiritual because the healing takes place in the therapeutic relation of a therapist and a client. Spirituality refers to an individual's experience that provides a greater sense of inner peace, harmony, hopefulness, and compassion for others and oneself. The term spiritus in Latin means "the breath" that is most vital to life. It involves an individual's experience of and relationship with a fundamental, nonmaterial aspect of the universe that may be referred to in many ways: God, higher power and mystery. In turn, this relationship produces fruit (such as altruism, love, or forgiveness) that has a discernible effect on an individual's relationship to self, nature, others, and the Ultimate (Carroll, 1997; Sermabeikian, 1994).

Since both counselling and spirituality focus on the same goal, which is the general well-being of an individual, there is a greater need to understand the relationship between counselling and spirituality. Therefore, this article intends to explore the therapists' views and experiences on the use of spiritual ingredients in counselling.

The importance of spirituality in counselling is highly recognised and discussed. Theologians have been writing and thinking about spiritual life for centuries, but now psychologists are also interested in spirituality as evidenced by a flurry of books on spirituality being published by the American Psychological Association (Miller, 1999; Richard \& Bergin, 1997, 2000; Shafranske, 1996). Therefore, an appropriate integration of counselling and spirituality is a need today. We are moving toward the merger of 
scientific and spiritual cultures. According to eminent psychiatrist Narendra Nath Wig, "The spiritual dimension is an essential and important aspect of health, particularly mental health."(p.16) Furthermore, assessment of spirituality is an emerging area of research among the mental health professionals, but most such researches that were conducted do not directly address spiritual ingredients in counselling and the therapist's views and experiences. Shafranske and Malony (1996) hold the view that psychologists have an ethical obligation to consider the religion and spiritual life of their clients just as they would consider their other cultural characteristics such as race, ethnicity, and sexual orientation. Mohan Das (2008) points out that a "spiritual dimension" which has received support from $80-90 \%$ of the population worldwide is largely left out by the mainstream mental health systems. However, he reiterates that therapists should not incorporate any such practices blindly without substantiating and validating them through intense scientific scrutiny.

Psychology and spirituality are coming together in strange and unexpected ways. Spirituality, anathema in Freud's time, is today setting the agenda for changes in psychology's understanding of humans, their motivations, the purpose for living and relationship with the universe. Perhaps the most uniting factor in the Indian context is that Indians, by and large, are believers. Ancient Indian thought is a storehouse of rich psychological insights elucidating explicit and subtle nuances of processes and constructs such as mental health and illness, cognition, emotion, attention, motivation, perception, self, and personality. Twentieth-century Indian philosopher and spiritualist Sri Aurobindo, based on his experiences and thorough study of ancient Indian philosophy, constructed an evolutionary map of consciousness. He observed that true liberation is not a flight from the material world into a spiritual world but is possible only by a unification of two ends of existence, the spiritual summit and the material base (Sharma, 2009). This research once again reiterates the need for a holistic approach, where we consider the human being as total: mind, body, and spirit. 


\section{Review of Literature}

Spirituality as a domain of study has acquired in itself much importance owing to its influence in the varied fields of human behaviour including coping ability, self-esteem, and realisation of self-strengths, in recovery from divorce, sexual assault, homelessness, and drug addiction. Spiritual intelligence is concerned with meaning, values, and creative vision, and most importantly has the power to transform. A highly developed Spiritual Quotient (SQ) includes flexibility, self-awareness, and capacity to face and transcend suffering, being inspired, not causing harm, being holistic in outlook, seeking answers to fundamental questions, and having the capacity to work against convention (Danah, \& Ian, 2000).

Many positive psychologists (Peterson \& Seligman, 2004; Snyder \& Lopez, 2002) have hypothesised that a deep understanding of ourselves and our lives is enhanced by our search for the sacred. Research findings also reveal that these pathways to the sacred may lead to (or at least are associated with) well-being. Also, spirituality gives purpose and meaning in our lives. We have discovered that there is a set of human strengths that are the most likely buffers against mental illness: courage, optimism, interpersonal skill, work ethic, hope, honesty, and perseverance. Much of the task of prevention will be to create a science of human strength whose mission will be to foster these virtues in young people (Seligman, 2005).

Powell (2009) reveals that one of the most common expressions of spirituality is "Prayer." Prayer often refers to asking a higher being for help, understanding, wisdom, or strength in dealing with life's problems. Prayer can be practised in several forms including a silent word of God or as a congregation. Regular attendance at a church, temple, or mosque may involve prayer, which focuses on one's self (supplication) or others (intercessory prayer). In this type of setting, the entire congregation may be asked to pray for a sick person or the person's family. Even simple practices such as silent observation, listening, or gratitude can become part of an openended spirituality that can be a part of everyday life. 
In the central teaching of Christianity, forgiveness is emphasised in the Lord's Prayer. Such forgiveness requires that the person seeking forgiveness must unequivocally also forgive those who have done wrong against him/her, and in the Christian belief, such forgiveness moves from God alone. This process has profound healing implications for Christians.

Wig (2009) has expressed his views regarding the subject of spirituality in the context of the Indian philosophy of religion and life. He is of the opinion that the world is a cyclic phenomenon or a continuum like the Chinese concept of "yin" and "yang" as a result of which there is more acceptance of conflicting views. According to him, mental health is dependent upon the concepts of Dharma, Kama, Artha and Moksha. Dharma is righteousness, virtue, or religious duty. Kama refers to the fulfilment of our biological needs or sensual pleasures. Artha refers to the fulfilment of our social needs and includes material gain, acquisition of wealth and social recognition. Moksha which is a very typical Indian concept means liberation or release from worldly bondage and union with the ultimate reality.

West (2000) discusses the dynamics of spirituality in therapeutic encounters; he argues that it involves a willingness to accept spirituality within the therapist, within the client, and within the therapeutic encounter. He has drawn his conclusions from his personal experiences: therapy, training and research, and his work with his clients. Ellison and Levin (1998) argue that spirituality is a key strength in personal well-being. Spirituality touches a wide arena of fields including mental health (Ventis, 1995), coping ability (Pargament, 1997), self-esteem (Ellison, 1993). It is also a significant variable in recovery from divorce (Kennedy, 1995).

Looking at counselling holistically, a healthy sense of self would be one in which body, mind, and spirit are joined and at peace with each other. These three areas in recent times have been confined and compartmentalised to their respective areas of expertisemedicine, psychology, and religion. Holistic counselling attempts to rejoin again these fragmented but connected areas of our lives. Reconnection with the parts of us, with each other, with our 
communities and our environments, is the call to healing across many disciplines (Sherwood, 1998).

Hill (2000) discusses the relation among religion, spirituality, and health. The author highlights recent advances in the description of religion and spirituality concepts and points to areas for growth in religion and spirituality conceptualization and measurement. If a counsellor does not raise the issue of how spirituality influences clients, then clients might assume that such matters are not relevant for counselling. Religion and spirituality are often part of the client's problem, but can also be part of the client's solution. Because spiritual and religious values can play a majorpart in human life, spiritual values should be viewed as a potential resource in therapy rather than as something to be ignored. Rowan (2005) considers spirituality so important that he thinks all counsellors should practice spirituality. He suggests that therapists should carefully explore their own attitudes towards spirituality and they equip and inform themselves about spiritual issues. Spirituality gives meaning and direction to a person's life and answers important dimensions of life such as the quest for meaning, purpose, self-transcending knowledge, meaningful relationships, love and commitment (Swinton \& Pattison, 2001).

\section{Methodology}

According to Franklin and Jordan (1995), spirituality seems better served by qualitative assessment methods. Qualitative approaches tend to be holistic, open-ended, individualistic, ideographic, and process oriented. They offer strength in assessing clients' spiritual reality, where the richness of information can be of particular importance. A therapist who integrates spirituality in practice can have a better picture of the client. In this study, the focus was on the experience of the mental health professionals on the spiritual ingredients in counselling. Therefore, a semi-structured interview schedule was used. This interview schedule was prepared after the field visit and interaction of the researchers, repeated interviews with the participants and discussions with the experts in the field, mental health professionals, etc. As the sample was purposive, the researcher could maintain the flexibility of interviewing the participants focusing on qualitative data. The schedule could also 
protect the qualitative nature of certain questions and understand the intensity of phenomenon of the experiences and views of each participant. The researchers obtained various institutional permission and approval to conduct this research as well as informed consent from all the participants.

Qualitative data analysis consists of identifying, coding, and categorising patterns found in the data. In the present study, thematic analysis was used. The process involved the identification of themes through careful reading and re-reading of the data. It was a form of pattern recognition within the data, where emerging themes become the categories for analysis. In this study, the major themes that had emerged were clustered in the process of analysis. The thematic analysis in this study showed that concepts formed from the data accurately capture and reflect the views and experience of the participants.

\section{Participants}

The participants of this study were mental health professionals from various reputed institutes of India. Participants are named: A, B, C, D, E, F, G, Hand I (names changed for confidentiality).

A is from Psychiatric Social Work background having 30 years of experience in the field of Psychotherapy and Counselling. A has a special interest in spirituality in the context of the therapeutic alliance.

B is a Professor of Psychiatry with 35 years of experience in the field of Mental Health. B has written on spirituality and mental health and worked with diverse groups. B has done tremendous work in the field of Mental Health especially using the regional language, Kannada.

C is a Professor of Counselling Psychology with 18 years of experience in counselling and psychotherapy to his credit. $\mathrm{C}$ is specialised in pastoral counselling. In addition to that, $C$ has a wealth of experience in the field of family counselling and youth ministry. 
D has a Ph. D in Counselling Psychology. D has 20 years of experience in counselling and formation, individual counselling and group therapy. D comes from a Christian background and uses many of spiritual elements in the process of counselling work.

$\mathbf{E}$ has 32 years of experience in therapeutic practice. $\mathrm{E}$ is an expert in alternative healing. A psychotherapist, E extensively uses spirituality in interventions. $\mathrm{E}$ has also has much work experience with trauma and crisis management.

F is a medical doctor trained in psychotherapy and counselling. F is an advocate of spirituality in interventions. $F$ has 17 years of experience in the field.

G has 18 years of experience in psychiatric social work and family therapy. $G$ is interested in meditation and other relaxation techniques.

$\mathrm{H}$ is a trained psychotherapist and has had a sparkling career of over 18 years. $\mathrm{H}$ is a trainer and a mentor in the field of psychotherapy and counselling. $\mathrm{H}$ is much interested in Rational Emotive Behavior Therapy (REBT) and Spirituality.

Iisa veterancounsellor and psychotherapist. I has done extensive research on spirituality and mental health spanning a period of 22 years.

\section{MajorFindings}

The participants of the research uphold the view that a person undergoing a counselling session has to be dealt with from a holistic perspective that includes body, mind and spirit. Although all those who participated in the research emphasised the importance of these elements, their views on the essentiality of the same differed. However, all the participants shared a common view that spirituality is an importantelement in the counselling process.

One of the participants, C, shared the view that counselling is basically born out of spiritual experiences between individuals and the rapport between the therapist and the client reflects spiritual elements like trust, respect, hope, and optimism. He felt that in 
spite of its importance, spirituality is not considered as an essential ingredient in the counselling process. Psychology has historically dealt with care of the mind as the cognitive process, the heart, as the affective process, and the body, as the behavioural process. The need to look at the soul as well with the realisation that the world today has the greatest need of addressing this element in human beings and counselling needs to address every iota of the individual.

These findings also show that there is an actualizing tendency in human beings, which leads to the higher power or transcendental element. The proponents of the humanistic school like Abraham Maslow and Carl Rogers stress the point of self-transcendence against the concept of secular counselling of self-fulfillment. The basic premise here is that psychological well-beingis closely interconnected with spiritual well-being. Participants in this study felt that therapists may not be equipped with the varied types of interventions involving spiritual elements because of the limitation in their training. This result also affirms that spirituality plays an important role in many aspects of mental health such as positive mental health, counselling, and psychotherapy. Hence the spiritual outlook of the therapist will influence the therapeutic process he/she adopts with the client.

A majority of the participants felt that spirituality failed to play a role when the clientwas not inclined toward it. However, a therapist who practices spirituality can spontaneously influence the client. Once a therapist is trained particularly in the use of spirituality and the tools for transformation of individuals, it can equip the therapist to use spiritual elements even with people who do not recognise the spiritual side of their lives. The major themes that emerged through data analysis are:

1) the basic aspect of spirituality is faith in God and a trust in some supernatural force and ability to connect with God may give meaning and purpose to one's life

2) the power of prayer has proved beneficial; it helps the patient to cope with the pain and suffering 
3) forgiveness is an art and forgiveness is key to mental, spiritual and bodily well-being and

4) a person must be considered as holistic through hope and confidence both of which play crucial roles in healing.

\subsection{Theme One: The basic aspect of spirituality is faith in God and a trust in some supernatural force and ability to connect with God may give meaning and purpose to one's life.}

Four of the participants (ACDE) responded that they associate this element of God/cosmic power/supreme concerning those areas of human life where science fails to give an approving or satisfactory answer. The participants have not only referred to the concept of God but have also referred to other concepts such as higher power/supreme/bigger design/ultimate/universal energy, etc. "One of the basic aspects of spirituality is belief in God and belief in some supernatural force. Trusting oneself is very important. It is also important that we are able to connect with a higher power that can be God or Supreme Being. There are also times when science cannot answer certain questions." (Participant A)

In exploring the views and experiences on the Higher Power, two of the participants shared, that connecting with God or the supreme power is one of the most important aspects of spiritual elements in counselling, as the concept of God has a great significance in the life of any individual. God, being the most fulfilling promise and hope of a person's life, must be given due importance while considering a person's spiritual background in counselling.

The role of the therapist is crucial in facilitating appropriate diagnosis. Spirituality is a resource for people coping with stress and daily struggle. "Connecting with God helps them to facilitate non-judgmental attitude and going within and going above a consciousness dimension. Connecting with higher power and connecting with one's own higher power. Therefore, they can go beyond." (Participant C) 
Therapists' training and skills are vital components for the effective therapeutic outcome. Also, if the clientis oriented to spirituality, the process will be smooth.

\subsection{Theme Two: The power of prayer has proved beneficial; it helps the patient to cope with the pain and suffering.}

The findings also revealed the importance of prayer, meditation, and rituals. Six of the participants (DEFGHI) responded that rituals are a means of expressing one's gratitude and belief have at all times been accorded with great respect and reverence. Observance of rituals can be regarded as an important means of ascertaining a person's spirituality and thus, prove vital to the whole process of counselling. All the participants were in agreement that prayer is an effective tool for better therapeutic outcome.

"I am somebody who believes in thepower of prayer. I go to the temple; I pray. As a Hindu, I can connect with Krishna or Vishnu etc. However, it makes me humble. As a therapist, these elements have helped me for better interventions. The strength of prayer comes in terms of relaxing me, helping me to focus and concentrate. So I could use it more for coping mechanism than as religious rituals. So, some of the clients are ready to accept these elements. But those who are already religious and spiritual in nature, it becomes an integral part of them."(Participant D)

Prayer is the most powerful component among the spiritual ingredients. The effective use of prayer helps the client to calm himself, gives hope and new direction. Besides, prayer is an integral part of rituals in Indian families.

Prayer is a high-quality intervention, and it is not limited to any particular religion. Besides, prayer makes a person calm, relaxed and peaceful. Moreover, reflective reading of the Scriptures can be found meaningful and helpful. "I personally believe that there is lot spirituality can do for a therapist. Why because spirituality speaks to you deep to address the core of your being. You look at who you are and what you are. From the personal experience, I point to where reading the Scriptures, qualifying my core are very 
beneficial to the counsellor, and I can direct my client." (Participant E)

All participants were of the opinion that where medicine failed to bring positive results, prayer has proved beneficial; it may not be effectual in fully curing the ailment, but it is effective in helping the patient to cope with the pain and suffering that he/she is experiencing. Although science has not successfully proved the true impact and implications of intercessory prayers, most people and religious organisations have always upheld the positive effects of it.

\subsection{Theme Three: Forgiveness is an art and forgiveness is the key to mental, spiritual and bodily well-being.}

Six of the (ABDFGH) participants shared their experience that hatred, hurt feelings and traumatic experiences make it difficult to practice forgiveness, but a therapist can teach his/her clients the art of forgiveness which will help them to manage themselves for the rest of their lives. Forgiveness is the key to mental, spiritual and bodily well-being. One of the participants shared the view that how forgiveness can be effective in painful and traumatic situations.

"A young man thirty years old dying of cancer in a hospice where I spent some time. A very angry man with God and with people, he did not want to talk to me, and he was resentful about the fact that a priest had come to visit him. However, he just shared something to vent his anger towards people and God, and he did not care about them. I continue to explore; I could see that he anchored a lot of anger with him, with his immediate family and with his friends. I continued to work with him, and gradually I saw a remarkable change in him. He became cheerful, and he reconciled with some of his family members. In fact, he responded physically as well. In this context, forgiveness and dying with hope are crucial elements." (Participant G)

When one holds on to one's pain or resentment, one burdened by them; however, when one forgives one feels light hearted and relieved. It does not mean that one should forget everything. Forgiveness is the core constituent of spirituality and forgiveness can lead to acceptance. Above all, forgiveness leads to reconciliation and better relationships. 
Forgiveness can lead to acceptance. Results show that forgiveness helps a person achieve Reconciliation and facilitates healing. In addition to that, forgiveness is the starting point for therapeutic healing.

"This is something which I was waiting for because forgiveness is one of the crucial elements when people learn to forgive themselves or others many people talk about acceptance. For terminally ill people also, it is important. I had an experience with a terminally ill child who was on oxygen, and he lived five years after that. Because when he was helped he said the main problem was about three events in his life which he could not forgive. Then 1 told him any way you are going why you don't forgive them. That seemed to relieve his breathing, and he got out of that, and it was surprising. Medically, it was not explainable. He got out of his problem very fast. So I find even there, forgiveness was very important." (Participant B)

As previously stated, forgiving a person who has done one harm is the first step in the healing process. In terminally ill people it is often seen that on practicing forgiveness their coping skills improve besides instilling in them more hope. In the Christian context, forgiveness has been given priority through confession and even through the Lord's Prayer which according to Christians is the greatest prayer ever known.

\subsection{Theme Four: A person must be considered as holistic through hope and confidence both of which play crucial roles in healing.}

All the participants (ABCDEFGHI) were in agreement that hope and optimism are the effective dimensions of spirituality on which the entire 48 counselling process is grounded. The therapist should be a person who facilitates hope, optimism and confidence in his/her personal life.

"One of the things I feel is optimism, and the next is hope. Then I go on continuously giving the optimism and hope in therapy. Then the faith in a higher level helps me to go ahead in spite of many failures. Let me do my best and let nature take care of the rest. When I do this, the client also gets the confidence, faith and hope above all the other things. So I have a sense of humour, I empathise 
with him/her. So these kinds of positive elements help me to go further with my therapeutic process". (Participant A)

A person with the most appropriate world view is seen as holistic. Furthermore, hope and optimism are the constituent elements for harmonious relation and successful living. Also, he/she can be creative and humorous.

"Actually if you look at spirituality it is all positive. The most positive thing is expanding the consciousness of that individual to go beyond his own personal or immediate problems looking at a bigger future not getting stuck in the past and exploring all the possible in the individual with hope and optimism." (Participant $\mathrm{H})$

As goes the saying, "Hope springs eternal in the human breast; human beings are creatures of hope"(Pope, 1734). The hope of a better tomorrow is what leads us through today. Faith and hope are interconnected. Faith can be called the alpha point of hope. Counselling plays a pivotal role in reinforcing hope in people who have undergone severe crisis.

\section{Implications}

The goal of application of spirituality in counselling is to help individuals and couples to achieve healthy, satisfying, and intimate relationships. Clients who have had a transformative experience in therapy, without exception have felt cared about, respected, and deeply understood by their therapists who have got in touch with spiritual elements.

Compassionate therapy will help one to regain a sense of safety, empower one to handle one's own life, establish a support system, and find a way to return to normalcy. The skill of empathy is the starting point for a therapist to build a therapeutic alliance. Spiritual elements like faith, trust, and love are vital to this process.

Forgiveness and empathy are important for a meaningful, happy life. It is much easier to understand the importance of forgiveness than actually to practice it. It is time to integrate spirituality and psychotherapy when a client is faced with different life situations and difficulties like mourning the loss of a loved one, trying to cope 
with a serious illness, having difficulty getting along with teenager, feeling exhausted from taking care of an elderly parent and confronting some other crisis or life transition.

At any time, we can face uncertainties and experiences that threaten our emotional and spiritual well-being. Caught off-guard by the numerous crises and transitions that accompany life, we may not know how to cope or where to turn for help. In this situation, a therapist who is trained with spirituality can be more successful.

Some people turn to psychologists, psychiatrists, and social workers for help in coping with these crises and transitions. Others look for support and the opportunity to discuss these issues within a spiritual context. But can one find spiritual help and psychotherapy at the same time? Most religious leaders have little time or training to provide in-depth and extensive therapy. Most psychotherapists have little training or desire to discuss in-depth spiritual matters during sessions with clients. There is an emergency for counsellors and psychotherapists who are competent to cater to the needs of clients from different walks of life, especially focusing on spiritual ingredients as part of their interventions.

Every person at some point in his/her life will search for the true meaning and purpose of life which automatically transforms into the search for something bigger than himself/herself. When confronted with a problem people tend to look beyond that problem which ultimately leads them towards spirituality. Moreover, crises and transitions are sometimes addressed in terms such as faith, meaning, purpose, and direction, as well as in psychotherapeutic terms. Therefore, training of a counsellor or a therapist can also include the fourth dimension of spirit other than mind, body, behaviour.

As in any other theory, spiritual approaches can be incorporated into counselling education. It is indeed, the need of the hour that in the training of a counsellor or a therapist, due importance is to be given to spirituality. Moreover, in the clinical service spirituality can be an effective building block. 


\section{Conclusion}

The spiritual journey of a client is nearly always a reflection of important themes in that person's life. This study indicates that spirituality plays a significant role in clients' lives. It is time for therapists and their trainers and supervisors to relate to the reality of their clients' spiritual lives and to look beyond any prejudices that they may have relating to religion and spirituality.

There are times when science cannot answer certain questions. Here comes the role of the therapist to use spirituality as an element for better processing and intervention. Trusting oneself is very important. It is also important that we can connect with a higher power that can be God or Supreme Being/Higher power. Though spirituality has exhibited its influence and importance over the years, mental health professionals have not given due regard to spirituality as a vital part of counselling intervention all over the world. Therefore, we need research on cross-cultural spiritual elements affecting clients' lives and comprehensive spiritual assessment tools for clinical and non-clinical population.

It is beneficial for a therapist to be in touch with his/her own spiritual life. It will be an added advantage that the therapist knows which particular element of spirituality can or cannot work for a client to attain a particular objective aimed for a better outcome. Self-awareness of the therapist is the most important element here. However, fundamentalism - a rigid way of looking at religion- and overemphasis on spirituality can be obstacles in the process of counselling. Too much emphasis on prayer and the God element can also be a block. The impact of rituals on daily life is another area that a therapist needs to be competent to understand a client.

Spirituality may be defined as the ability and the tendency present in human beings to find and construct a meaning about life and existence and to move toward personal growth, relationships and relation with others.

Psychologists have been hesitant to recognise other dimensions of healing, such as spirituality, seeking instead causal connections for illness. The cause and effect theory alone should not become the 
priority while treating clients, but the clients' spirituality must be given due weightage seeking the fact that it is not just mind and body but the person in total who needs care and respect.

Spirituality is ever more recognised as an important client-strength that often facilitates well-being from Eastern and Western points of view (Wig, 2009).Since many of the research institutes in the United States are studying the relevance of spirituality in mental health, it is also very important to train spiritually competent therapists. We need to open new vistas in this direction. This evaluation lays the foundation for the use of spiritual interventions that can help clients deal with problems and improve their lives. Even though many practitioners are interested in using spiritual interventions in clinical settings, this research indicates that they have frequently received little training on this topic. Therefore, this study highlights the importance of integration of spirituality into counselling interventions.

\section{References}

Bergin, A. E., \& Jensen, J.P. (1990). Religiosity of psychotherapists: A national survey. Psychotherapy, 27(1), 3-7.

Carroll, P. (1997). Spiritual life maps: A client-centered pictorial instrument for spiritual assessment, planning, and intervention. Canada: Reference Publications.

Cashwell, C. S., \& Young, J. S. (2004). Spirituality in counselor training: A content analysis of syllabi from introductory spirituality courses. Counselling \& Values, 48, 96-109.

D.B., \& Zinnbauer, B.J. (2000). Conceptualizing religion and spirituality: Points of commonality, points of departure. Journal for the Theory of Social Behavior, 30, 51-77.

Ellison, C.G., \& Levin, J.S. (1998). The religion health connection: Evidence, theory, and future directions. Health Education and Behavior, 25(6), 700-720.

Franklin, C., \& Jordan, C. (1995). Qualitative assessment: A methodological review. Families in Society, 76, 281-295. 
Gartner, J., (1996). Religious commitment, mental health and prosocial behaviour: A review of theempirical literature. In E.P. Shafranske (ed.), Religion and the clinical practice of psychology (pp. 43-48). Washington DC: American Psychiatry Association.

Hill, P.C., Pargament, K.I., Hood, R.W. (Jr.), McCullough, M.E., Swyers, J.P., Larson Hodge, D. R. (2000). Spiritual ecomaps: A new diagrammatic tool for assessing marital and family spirituality. Journal of Marital and Family Therapy, 26, 229-240.

Hodge, D. R. (2001) Spiritual Assessment: A Review of Major Qualitative Methods and a New Framework for Assessing Spirituality. Canada: Reference Publications.

John, R. (2005). The Transpersonal: Spirituality in Psychotherapy and counselling. U. K.:Routledge.

Kennedy, J. E., Davis, R. C., \& Taylor, B. G. (1998). Changes in spirituality and wellbeing among victims of sexual assault. Journal for the Scientific Study of Religion, 37, 322-328.

Koenig, H.G., McCullough M.E., Larson D.B. (2001). Handbook of religion and health. New York: Oxford University Press.

Mohandas, E. (2008). Neurobiology of spirituality. Mens Sana Monographs, 6(1), 63-80.

Murray, R.B. \& Zentner, J.P. (1989). Measuring concepts for health promotion. London: Prentice Hall.

Pargament, K. I. (1997). The psychology of religion and coping. New York: Guilford Press.

Patterson, C. H.(1964). Modern approaches to counselling diagnosis. Journal of Counselling Psychology, 11(3), 297-298.

Pope, A. (1734). An Essay on Man: In Epistles to a Friend (Epistle IV). (1st ed.). London: J. Wilford.

Powell, A. (2009). Furthering the spiritual dimension of psychiatry in the United Kingdom. In A. Sharma (Ed.), A book on spirituality and mental health (pp. 263-281). Delhi: Indian Psychiatry Society, Medical wing, RERF.

Rowan, J. (2005). The Transpersonal: Spirituality in Psychotherapy and counselling. London \& New York: Routledge 
Seligman, M. E., Steen, T. A., Park, N., \& Peterson, C. (2005). Positive psychology progress: Empirical validation of interventions. American Psychology, 60(5), 410-421.

Shafranske, E. \& Malony, H. M. (1990). Clinical psychologists' religious and spiritual orientations and their practice of psychotherapy. Psychotherapy, 27, 72-78.

Sherwood, D. A. (1998). Spiritual assessment as a normal part of social work practice: Power to help and power to harm. Social Work $\mathcal{E}$ Christianity, 25(2), 80-100.

Swinton, J. (2001). Spirituality and mental health care: Rediscovering a forgotten dimension. London: Jessica Kinglsey Publishers.

Swinton, J., \& Pattison, S. (2001). Spirituality: Come all you faithful. Health Services Journal, 111(5786), 24-25.

Tyler, D. E. (1969). The work of the counsellor. New York, N. Y.: Appleton- Century- Crofts.

Tyler, P. (2010). Healing the butterfly: Reflections on the relationship between psychotherapy/counselling and Christian spiritual direction.Vinayasadhana: Journal of Psycho-Spiritual Formation, 1, 39-42.

Ventis, W. L. (1995). The relationship between religion and mental health. Journal of Social Issues,51(2), 33-48.

West, W. (2000). Psychotherapy \&Spirituality: Crossing the line between therapy and religion.New Delhi: SAGE Publications Ltd.

West, W., \& Moodley, R. (2005).Integrating traditional healing practices into counselling and psychotherapy. New Delhi: SAGE Publications Ltd.

Wig, N. N. (2009). Mental health and spiritual values: A view from the east. In A. Sharma (Ed.), A book on spirituality and mental health (pp. 3-21).Delhi: Indian Psychiatry Society, Medical wing, RERF.

Young, J. S., Wiggins-Frame, M., \& Cashwell, C. S. (2007). Spirituality and counsellor competence: A national survey of 
American Counselling Association members. Journal of Counselling \& Development, 85, 47-52.

\section{Appendix}

Questionnaire

To explore the views and experiences of therapists on spiritual elements in Counselling

1. Do you think Spirituality is an important ingredient in Counselling? And how?

2. What are the spiritual elements to be kept in mind as a therapist during Counselling?

3. How much do you use these Spiritual elements in counselling?

4. How do you translate the term like connectivity with the world / being one with supreme power in a counselling session?

5. How do you address things like faith healing, offering to church or temple, extreme dependence on penitential prayers than bringing change or practice?

6. What outcomes in clients have you seen after using spiritual elements? Has that increased spiritual well-being alone/holistic improvement?

7. According to you who can practice spiritual elements in counselling? What are the pre requisites?

To establish the role of spirituality in the process of Counselling

1) Could you please share which are the positive dimensions of spirituality that influence the course of Counselling?

2) What intervention do you use in counseling in terms of spiritual components like Bibliotherapy, spiritual books or prescribing any rituals and so on?

3) When do you use spiritual elements in the process of counselling? 
4) What factors do you assess to understand client's spiritual inclination?

5) Do you think the Spiritual Aspects of Human Beings should be cared about in Counselling?

6) In what ways do you think a therapist can make use of the client's spiritual inclination? (E.g.; Instill positive thinking, concern for fellow beings)

7) When do you not consider these spiritual dimensions?

8) When the client is not interested in these elements or spiritual beliefs, how do you address them?

9) Will you recommend the same intervention to two people with the same problem, but at different levels of spirituality? How will your approach differ?

10) What kind of therapist's issues do you see in using spirituality in counselling, context like religious/nonreligious persons?

To explore the Relation between Religious Beliefs and the Healing Process

1) Do you think Religious Belief is an effective element in the Process of Healing?

2) What are the aspects of spirituality or religion that have a negative influence in achieving the desired results in Counselling? (E.g.: Feeling of guilt, fixation on certain beliefs, rituals etc.)

3) Do clients from different religious backgrounds show marked changes in their value system? Can you offer a comparison based on your experience?

4) What is the role played by spiritual elements such as forgiveness, hope and faith in the healing process?

5) Do you think that therapist beliefs help for a better therapeutic relationship? When they differ how do you process it? Is it necessary to bring them to your view point? 
6) How do you handle issues of false beliefs/ false religious teachings in connection with nature, nurture and sciences? What ways to approach to correct that cognition without affecting the religious morals?

7) As a therapist what are the changes you noticed (improvements) using spiritual elements in your life?

8) How do you improve your spirituality? 